\title{
DEMOCRACIA CRISTÃ E POPULISMO: UM MARCO HISTÓRICO COMPARATIVO ENTRE O BRASIL E O CHILE
}

\author{
Sandro Anselmo Coelho \\ Universidade Federal do Paraná
}

\begin{abstract}
RESUMO
O objetivo deste artigo é indicar de que forma a Democracia Cristã, no Brasil e no Chile, articularam-se com o populismo. O periodo histórico brasileiro escolhido para análise é o da chamada democracia populista (1945-1964) e o chileno é o da presidência de Eduardo Frei Montalva (1964-1970).
\end{abstract}

PALAVRAS-CHAVE: democracia cristã brasileira; democracia cristã chilena; populismo; partidos políticos brasileiros (1945-1965).

\section{INTRODUÇÃO}

No que se refere aos estudos sobre a política brasileira, notamos que os principais partidos políticos do período situado entre 1945 e 1964 sempre receberam muita atenção dos pesquisadores. Todavia, cabe ressaltar que são poucos os registros de trabalhos sobre o Partido Democrata Cristão (PDC), mesmo tendo sido este aquele que, percentualmente, mais cresceu no legislativo nacional entre 1954 e a edição do Ato Institucional n 2 , em 1965.

De nossa parte, importa indicar que os pedecistas brasileiros conseguiram se estabelecer com significância no quadro partidário brasileiro, principalmente a partir de 1962, quando a democracia populista estava já em profunda crise. Gostaríamos de destacar, nesta discussão, que a Democracia Cristã (DC) brasileira conseguiu, no âmbito do Congresso Nacional, entre 1954 e 1962, saltar de duas para vinte cadeiras ${ }^{1}$. Esteve, portanto, praticamente em igualdade numérica com o Partido Social Progressista (PSP), de Adhemar de Barros,

1 Na legislatura de 1955-1959, os democrata-cristãos contavam com 2 deputados, na de 1959-1963 passaram a 7 e entre 1963 e 1967 contaram com 20. Nesta legislatura, o partido foi muito inferior ao Partido Social Democrático (PSD), que detinha 118 cadeiras, ao Partido Trabalhista Brasileiro (PTB), com 117 cadeiras, e à União Democrática Nacional (UDN), que possuía 91 deputados. que obteve, em 1962, vinte e uma cadeiras. Tendo em conta que o PSP vinha perdendo assentos desde 1954, identificamos como bastante provável que, caso em 1966 houvesse normalidade no processo político-partidário, o PDC tornar-se-ia a quarta força no legislativo nacional.

A relevância da DC brasileira pode também ser constatada se focarmos o Executivo federal e dois Executivos estaduais. Na esfera executiva federal, o partido obteve o Ministério da Previdência Social, com André Franco Montoro no primeiro gabinete parlamentarista de João Goulart, e o Ministério da Educação e Cultura, com Paulo de Tarso Santos, no governo presidencialista de Goulart. Os democrata-cristãos brasileiros formaram, ainda, uma coligação com a UDN para a candidatura de Jânio Quadros à Presidência da República, em 1960. Observamos, outrossim, que o partido teve em suas hostes figuras que desempenharam importante papel na articulação política nacional: além de Jânio Quadros, que saiu do PDC antes das eleições de 1960, desse partido vieram os próprios Franco Montoro e Paulo de Tarso, Juarez Távora, Jarbas Passarinho, Nelson Marchezan (CHACON, 1981, p. 169), Plínio de Arruda Sampaio, Ney Braga e José Richa. Quanto aos Executivos estaduais, não podemos esquecer que os pedecistas brasileiros conquistaram o governo dos estados do Paraná, com Ney Braga, nas eleições de 1960, e de São Paulo, com Carvalho Pinto, em 1962.

Como dissemos anteriormente, poucos são os 
trabalhos acadêmicos que tratam especificamente do PDC brasileiro. Todavia, o fato de a DC não haver sido um agrupamento político que se limitou à realidade brasileira e, mesmo, por ter se fortalecido muito mais em outros países do que no Brasil, permite-nos acessar algumas pesquisas a seu respeito e que foram feitas em outros lugares. Dito isso, expomos o principal objetivo deste artigo: indicar de que forma a Democracia Cristã, no Brasil e no Chile, articulam-se com a categoria do populismo. O período histórico brasileiro escolhido é o da chamada democracia populista (1945-1964) e o chileno é o da presidência de Eduardo Frei Montalva (1964-1970).

A escolha do Chile como contraponto comparativo fez-se porque, em relação à América Latina, foi nesse país que a DC, em nosso ver, mais eficazmente se construiu como alternativa política. Mesmo considerando que a DC chilena apenas se constituiu em partido unificado em 1957, doze anos após a brasileira, sublinhamos que os democratas-cristãos daquele país, inclusive o próprio Frei, desde 1937, ao romperem com o Partido Conservador e fundarem a Falange Nacional, iniciaram uma conformação partidária que propiciaria um vigoroso processo de fortalecimento político da DC chilena. Os falangistas, que se entendiam como portadores dos princípios políticos do pensamento cristão, conseguiram disputar todas as eleições nacionais e, em 1952, Frei concorreu à Presidência da República, chegando ao segundo turno. Se, por um lado, a DC chilena foi mais lenta que a brasileira para unificar-se em um partido, posto que apenas em 1957 a Falange Nacional fundiu-se com o Partido Conservador Social-Cristão, por outro, os pedecistas chilenos lograram um sucesso mais eminente, o que fica bem demonstrado com a conquista, em 1964 - apenas sete anos após a fundação do seu partido - da Presidência da República. Nestas eleições, Frei obteve 55,7\% dos votos e Salvador Allende, do Partido Socialista, 38,6\%; vale destacar, também, que nas eleições parlamentares de 1965 a DC chilena obteve 42,3\% dos votos, ficando muito à frente do segundo colocado, o Partido Radical, que atingiu 13,3\% do eleitorado (PDC, 1968, p. 3).

Após essa breve introdução sobre as DC nos dois países, entendemos pertinente expor a maneira como este artigo vai se desenvolver. No sentido de estabelecermos o marco comparativo de nossa pretensão, buscaremos isolar uma variável que julgamos importante em nossa reflexão, qual seja, o estabelecimento das possiveis relações entre as DC brasileira e chilena com o populismo. Para obtermos maior clareza no debate, dividimos este trabalho em três partes, além desta introdução e das considerações finais. Na primeira parte, faremos um breve histórico sobre a DC, indicando seus principais pressupostos políticos, tanto no Brasil quanto no Chile. A seguir, posicionar-nos-emos face a importantes autores - Ludovico Incisa, Alain Touraine, Francisco Corrêa Weffort, Júlio Pinto, Gabriel Salazar e Octavio Ianni - que tratam da categoria populismo; além disso, debateremos o nacional-desenvolvimentismo. Na terceira parte, veremos em que sentido a DC, nas suas versões brasileira e chilena, relacionaram-se com o populismo; também discutiremos algumas questões acerca de sua ascensão a cargos eletivos haver sido menos visível no Brasil que no Chile.

\section{APROXIMAÇÃO AOS PRESSUPOSTOS POLÍTICOS E UM BREVE HISTÓRICO SOBRE A DEMOCRACIA CRISTÃ}

Para nos aproximarmos do tema da Democracia Cristã, iniciaremos com um breve histórico sobre sua conformação como alternativa política. Ao final da Segunda Guerra Mundial, a proposta democrata cristã surgiu como um movimento político autodenominado como distinto dos que até então se apresentavam no cenário políticopartidário internacional. Com isso, essa alternativa passou a conquistar uma relativa força eleitoral em diversos lugares, principalmente na Europa e na América Latina ${ }^{2}$. Os democratas cristãos apre-

\footnotetext{
2 Europa: na Itália, o Partido Popular de Luigi Sturzo, anterior a Mussolini, inspirou o PDC, liderado, de início, por Alcide de Gasperi; na Alemanha, tivemos a CDU (União Cristã Democrática)-CSU (União Cristã Social); na Áustria, a DC esteve no Partido Popular; na Bélgica, tivemos o Partido Social Cristão; mesmo na França, onde a DC não foi tão relevante como nestes países, o Movimento Republicano Popular (MPR) recebeu influência dos seus pressupostos (CHACON, 1981 : 168). América Latina: para além do Brasil e do Chile, tivemos a fundação da Organização Democrata Cristã da América (ODCA); na Venezuela, a DC organizou o Comitê de Organização Política Eleitoral Independente (COPEI); no Paraguai, o Movimento Democrata Cristão; na Nicarágua, o Partido Social Cristão; Guatemala, Peru, Uruguai, Bolívia tiveram seus PDCs; a Argentina teve núcleos de DC; no Panamá houve a União Cívica Nacional; no Equador, a DC Equatoriana; na República Dominicana, o Partido Revolucionário Social Cristão (VITALE, 1999, p. 115-116).
} 
sentavam-se e entendiam-se como diferentes das demais agremiações políticas por formularem uma pretensa terceira opção entre a democracia liberal capitalista norte-americana e a doutrina revolucionária socialista. Atuavam na "insistência sobre os valores familiares e sobre o papel das comunidades intermediárias, no respeito pela propriedade privada, na busca da participação nas relações de trabalho e no pluralismo político" (MAYEUR, 1999, p. 898).

No caso brasileiro, as propostas dos democratas cristãos alocaram uma aceitação mais tímida se comparada com, por exemplo, os contextos venezuelano e chileno. Todavia, tal acontecimento não se deu pela falta de iniciativa de seus signatários. No Brasil, a DC já vinha tentando organizar-se enquanto partido desde 1933, através da Liga Eleitoral Católica (LEC); no entanto, lembremos que o Estado Novo não permitiu a existência de nenhuma organização partidária. Somente em um contexto posterior foi que a revista $A$ ordem, fundada por Jackson de Oliveira e continuada por Alceu Amoroso Lima, em sua edição de julho-agosto de 1945 - portanto antes da queda de Getúlio Dornelles Vargas - propôs a criação de um PDC. Tal partido buscaria três objetivos políticos: elevar moralmente as massas populares, desenvolver uma participação popular no governo o mais profundamente possível e, por fim, que o Direito e a Moral coordenassem a vida política nacional e internacional. Outrossim, temos em $A$ ordem a defesa, como plataforma partidária, do sufrágio universal, o mais amplo possível, da autonomia e do respeito mútuo entre os Poderes Legislativo, Executivo e Judiciário, de um governo que fosse a expressão da harmonia entre estes três poderes, sem a proeminência do Executivo. Vemos ainda na revista o desejo de que os governantes tivessem responsabilidade sobre suas atitudes, o que seria conseguido com a publicidade de todos os seus atos (CHACON, 1981, p. 168).

Para lançarmos luz mais cuidadosamente sobre a fundação do PDC brasileiro, vemos relevância na discussão sobre aquele problemático contexto político nacional. Sendo assim, é fundamental ter em conta que, apesar de a ditadura de Vargas como administração pública direta ter conseguido por um bom tempo impedir o surgimento de partidos políticos, seu propósito não logrou uma longa duração. Afinal, um modelo de Estado que, para muitos, era facilmente identificável com o fascismo, possuía, depois da vitória dos Aliados na Segunda Guerra Mundial, cada vez menos condições de se manter. Isso se dava em alguma medida porque esse Estado, forçosamente ou não, havia enviado tropas para combater ao lado das potências democráticas liberais capitalistas justamente contra o totalitarismo europeu. Todavia, o fim da ditadura varguista deveria ser cuidadosamente orquestrado e não se dar ao ritmo de uma música que poderia comprometer o sistema político como um todo. As possibilidades de organização popular, que davam já os seus acordes, e num tom que não agradava aos ouvidos de uma elite política acostumada a impor seus projetos com autoritarismo, era vista como uma real ameaça. A partitura, a muito custo, foi elaborada. "O descontentamento popular deveria ser esvaziado, absorvendo sua liderança e tentando conseguir uma burocratização de suas demandas através de instrumentos de repressão pacífica como aqueles fornecidos pelo Estado patrimonial e cartorial" (DREIFUSS, 1981, p. 26). Antes de abandonar o Executivo, os estado-novistas conseguiram compor uma disciplinada harmonia notadamente populista, que, por um bom tempo, controlaria algum possível processo de politização da sociedade brasileira. Sendo assim, estabeleceuse "um esquema de limitada mobilização política nacional das massas urbanas, baseado em uma estrutura sindical controlada pelo Estado e no apoio institucional do PSD e do PTB" (idem, p. 27) ${ }^{3}$. Foi nesta quadra histórica asfixiante que o PDC buscou espaço para se solidificar no quadro político-partidário nacional, e, portanto, não nos admira que tenha demorado até 1962 para adquirir alguma expressividade.

Mas o PDC brasileiro só foi legalmente criado em 1945, em São Paulo, após o fím da ditadura de Vargas, sob a liderança de Cesarino Júnior, professor de Direito do Trabalho na Universidade de São Paulo. Esses democratas cristãos preten-

\footnotetext{
3 Sobre tal ponto, nessa mesma linha interpretativa, temos Souza, para quem "o advento do pluralismo partidário, de eleições diretas, e o retorno a separação formal dos poderes do Estado, determinados pela Carta Constitucional de 1946, foram superpostos ou acoplados à estrutura anterior, marcada pelo sistema de interventorias, por um arcabouço sindical corporativista, pela presença de uma burocracia estatal detentora de importante capacidade decisória, para não mencionar a plena vigência na quadra histórica a que nos referimos, de uma ideologia autoritária do Estado" (SOUZA, 1983, p. 106).
} 
diam tornar-se galvanizadores das reservas de energia da Igreja, bem como transmitir essas reservas a amplos setores sociais (VIANNA, 1981, p. 146). Na nossa compreensão, era o que lhes restava naquele período, dada a dinâmica do processo eleitoral existente, pois o PSD tinha um razoável controle sobre as classes subalternas camponesas, o PTB vinha se apoiando nas classes populares urbanas, e a UDN articulava praticamente todos os oposicionistas àquele modus operandi do sistema partidário brasileiro ${ }^{4}$.

Contudo, apesar dessa dinâmica do PDC brasileiro, de todos os países latino-americanos, foi no Chile da década de sessenta que a DC obteve melhores condições de um efetivo fortalecimento - vide a conquista da Presidência da República, em 1964, com Frei. Nessa questão, se observássemos o caso da Venezuela, onde o Comitê de Organização Política Eleitoral Independente (COPEI), um partido democrata-cristão, conquistou a Presidência em 1969, com Jovito Villalba, poderíamos compreendê-lo como um óbvio indício de fortalecimento da DC semelhante ao ocorrido no caso chileno. Porém, entendemos que, referindo-se ao país de Villalba, "a vitória da Democracia Cristã - ao contrário do que ocorreu no Chile em 1964 - não tenha tido uma ressonância considerável na opinião púbica continental, e, na própria Venezuela, haja sido encarada mais como um episódio da decomposição da ordem política caracterizada pela hegemonia eleitoral da Ação Democrática que como o início de uma nova experiência, ao mesmo tempo renovadora e vigorosa" (DONGHI, 1975, p. 298).

No que se refere à formação do PDC chileno, teremos uma indicação de pressupostos democratas cristãos organizados em partido se nos reportarmos à década de trinta. Ainda em 1937, os líderes da Juventude do Partido Conservador (Ignacio Palma, Jorge Rogers, Manuel Garretón, o próprio Frei e Bernardo Leighton) romperam com seu partido, fundando a Falange Nacional. Tal organização política se dizia fundamentada nos

\footnotetext{
4 Adotamos por sistema partidário o entendimento dado por Maria do Carmo Campello de Souza. Para esta autora, o sistema partidário "delineia como objeto de interesse o conjunto de relações dos diversos partidos entre si, com o corpo eleitoral e com os grupos de interesse, por um lado, e com os diversos aparatos que compõem o Estado, em sentido estrito, por outro" (SOUZA, 1983, p. 43).
}

princípios do pensamento cristão, que não estariam nem no comunismo nem no capitalismo. Defendia uma sociedade que não seria individualista ou coletivista, mas baseada nos preceitos da copropriedade. Visava a lutar contra os comunistas, os nazistas e os socialistas. De nossa parte, entretanto, pensamos não ser descabido localizar tal organismo político próximo da Falange espanhola.

Para debatermos essa questão, resgatamos a clássica obra sobre o PDC chileno, El Partido Democrata Cristiano chileno, de George Grayson Júnior, posto que ela nos servirá como importante ponto de aproximação aos pedecistas deste país. Esse autor indica que o líder Garretón esteve na Europa, ainda em 1934, e, ao regressar ao Chile, "había hablado de Mussolini como de un gigante, e del fascismo como el más interesante sistema para estudiar, el mayor intento de remediar los males del régimen democrático-liberal" (GRAYSON, 1967?, p. 145-146). Tal similitude fica por certo mais observável se olharmos para a estrutura organizacional que esteve presente, de início, entre os falangistas chilenos: "Bajo su mirada cuidadosa [de Rogers], los jóvenes recibieron uniformes y se estructuraram en equipos (quatro falangistas), secciones (quatro equipos) y grupos (quatro secciones). A la cabeza de cada grupo se hallaba un 'brigader', siendo el grupo la mayor unidad en la estructura militarizada de la Falange" (idem, p. 146). Mas seríamos injustos se ocultássemos que líderes como Frei, Radomiro Tomic e Leighton, de começo, questionaram esta forma de organização, conseguindo retirar o caráter militarista da Falange Nacional.

Porém, até o início dos anos cinqüenta, apesar de os falangistas terem concorrido a todas as eleições nacionais, atingiram pouca expressividade nas urnas. Foi somente a partir desse decênio que outra situação começou a se configurar: "Durante la década de 1950, el socialcristianismo chileno se convertió en un partido con vasta influencia popular. Para enfrentar la candidatura presidencial de Ibañez en 1952 intentó levantar una coalición de centro-izquierda com el Partido Radical, llegando Frei a la última vuelta, pero el PR quebró la alianza. En 1953, fue criada la Federación Socialcristiana con la Falange Nacional y el nuevo grupo escindido del conservantismo - liderado por Horacio Walker, Pablo Larraín, Pedro Undurraga y Jorge Mardones Restat - Partido Conservador Socialcristiano, los cuales se fusionaram en julio de 1957, dando nacimiento al Partido Demócrata 
Cristiano" (VITALE, 1999, p. 114). Estava fundado o mais importante partido político da DC na América Latina. Com efeito, cabe ressaltar que este PDC estava profundamente sintonizado com as propostas de terceira via de seus congêneres no Velho e no Novo Mundo. Demonstra isso sua declaração de que veio "para transformar desde dentro, por métodos democráticos y legales [...] las estructuras estabelecidas por un liberalismo individualista o por el totalitarismo coletivista" (GRAYSON, 1967?, p. 313).

Todavia, se tivermos em mente que tanto para o Chile como para o Brasil esteve evidente, entre os pedecistas, a proposta de construir uma alternativa política ao capitalismo e ao socialismo, identificamos em ambos os casos que o que se verificou foi muito mais um combate às reivindicações populares que não se acomodassem à ordem institucional vigente. Tal ocorrência pode ser bem averiguada se observarmos alguns posicionamentos políticos de democratas cristãos brasileiros e chilenos. No Brasil, por exemplo, os pedecistas estiveram próximos à UDN e à sustentação de suas propostas conservadoras. Uma boa demonstração disso foi o PDC apoiar, em 1960, como indica Maria Victoria Mesquita Benevides, a proposta de previdência social udenista que "manteria a exclusão dos trabalhadores rurais e domésticos do sistema previdenciário e limitaria a participação [dos trabalhadores] nos níveis decisórios das instituições" (BENEVIDES, 1981, p. 189). Para o Chile, tivemos a DC, quando no governo, reprimindo duramente as mobilizações populares, como foi o caso dos mineiros de El Salvador, em 1966, e os protestos de sem-tetos, em Puerto Montt, em 1969 (VITALE, 1999, p. 143). Ainda nesse sentido, apesar de não fazer parte das reflexões centrais deste trabalho, lembraremos o apoio que os dois PDC deram aos golpes militares de $1964 \mathrm{e}$ 1973, ocorridos, respectivamente, no Brasil e no Chile.

Outra questão importante é a verificação de que, a partir da consecução do PDC chileno, se compararmos a ascensão a cargos eletivos da DC nos dois países em foco, observamos que elas tiveram destinos diversos. Mesmo entendendo que a DC brasileira esteve em franco crescimento a partir de 1954, tal ocorrência será muito pequena se comparada às conquistas que os pedecistas chilenos galgaram apenas sete anos depois de constituírem seu partido. Antes de refletirmos sobre algumas questões acerca da diferença na ascensão aos cargos eletivos, sugerimos iniciar um debate sobre como, nestes países, a DC se relacionou com uma polêmica categoria, muito utilizada por intérpretes que se dedicam a história política latino-americana: a do populismo. Supomos que o estudo da maneira diversa como os dois países debateram-se com o populismo ajuda-nos a dissipar as nuvens sobre o problema das diferentes conquistas eleitorais dos democratas cristãos.

\section{POPULISMO: DISCUTINDO A CATEGORIA}

Ao tratarmos de história política na América Latina, diversos são os confrontos teóricos, metodológicos e conceituais. Se aportarmos nessas discussões, entre os termos mais polissêmicos que veremos, certamente populismo ocupa um lugar de prestígio; deparando-se com esse problema, um pesquisador já chegou a afirmar ser este termo uma difusa categoria que serve "como verdadeira panacéia da ciência política brasileira" (VIANNA, 1981, p. 155). Para nós, contudo, um termo tão disseminado entre os estudiosos da política latinoamericana não poderia ser deixado de lado quando se pretende compreender alguma faceta do espectro político do continente. Vamos, então, apreciar como reconhecidos pesquisadores entendem o populismo.

Partamos da definição proposta por Ludovico Incisa feita em importante dicionário político; ele compreende por populistas "as fórmulas políticas cuja fonte principal de inspiração e termo constante de referência é o povo, considerado como agregado social homogêneo e como exclusivo depositário de valores positivos, específicos e permanentes" (INCISA, 1999, p. 980). Haveria, para o autor, três categorias de movimentos populistas: nacional-populistas (fascismo, nacional-socialismo, Guarda de Ferro romena, peronismo e vários movimentos militaristas como, por exemplo, o nasserismo), populistas revolucionários (stalinista e castrista) e populistas democráticos ou pluralistas (democracia jacksoniana americana, sistema democrático israelense e gandhismo).

Esse pesquisador, quando se refere às possíveis relações entre a Democracia Cristã e o populismo, estabelece o seguinte: "o populismo se distingue dos movimentos de inspiração democrático-cristã. Isso não só por que tais movimentos apresentam interpretações teóricas orgânicas, mas também por que o populismo não se inspira em qualquer realidade religiosa transcen- 
dente. O deus do populismo é o próprio povo. [...] Mas também não se pode negar que alguns movimentos democrático-cristãos se harmonizam, em determinadas circunstâncias, com comportamentos de tipo populista" (idem, p. 984).

Notamos, dessa forma que, para Incisa, existe um certo espaço de movimentação que poderia servir para que a inter-relação entre populismo e DC viesse a ser feita. Assim, se adotássemos a perspectiva desse autor, poderíamos entender o PDC chileno como tendo a clara possibilidade de ser considerado portador de elementos populistas, pois, em 1964, no seu programa de governo, "llama a todos los chilenos - hombres, mujeres, niños - sin distinciones religiosas o de clase, que estén dispuestos para luchar democráticamennte por un nuevo orden social fundado en la fraternidad y en la justicia" (GRAYSON, 1967?, p. 336). Temos assim, no discurso pedecista, os caracteres de cunho religioso e de classe - outro ponto levantado por Incisa para caracterizar o populismo - sendo sobrepostos pelo caráter conciliador ${ }^{5}$. E mais: ao evidenciarmos que os pedecistas chilenos afirmaram visar à criação de uma nova ordem social, ou seja, transformar o establishment, eles são facilmente aproximados da definição que o autor aqui debatido propõe sobre populismo. Nessa situação seria possível classificar a situação da DC chilena como marcada por elementos identificáveis com o populismo, mais apropriadamente nas suas variações democrática ou pluralista.

No caso do PDC brasileiro, que teria, segundo seu programa de 1961, como um dos seus objetivos "conciliar, no campo econômico-financeiro, o exercício da livre iniciativa e o uso da propriedade privada, com as exigências do bem comum social e do direito à igualdade de oportunidades que deve ser garantido a cada brasileiro, para realizar seu bem-estar individual" (PDC, 1981 [1961], p. 472), podemos, sob os pressupostos de Incisa, facilmente entendê-lo como populista.

Entretanto, vemos nas apreciações de Incisa um conteúdo muito amplo dado ao termo, pois a referência ao povo, da forma como o autor expressa, é um artifício discursivo de que a imensa

\footnotetext{
5 Nas palavras do autor: "o populismo exclui a luta de classes: é fundamentalmente conciliador e espera transformar o establishment; é raramente revolucionário" (INCISA, 1999, p. 981 , grifo no original).
}

maioria dos políticos latino-americanos, na nossa ótica, e ao menos nos momentos de crise, lança mão, a fim de continuar mantendo o controle político sobre o aparelho de Estado. Sendo assim, parece-nos que, se adotássemos o seu conceito, correríamos o risco de acabar dissolvendo o termo populismo em uma diversidade muito ampla de quadros históricos.

Outra importante análise feita sobre a questão aqui abordada é a de Alain Touraine. Esse autor identifica que nas sociedades onde a modernização é, em grande medida, importada, surge a vontade política de se estabelecer um desenvolvimento que se contraponha à dependência externa e que mantenha ou regenere as características fundamentais da identidade nacional. Em suas palavras, o fenômeno ocorreria nos seguintes moldes: "Contra a prioridade dada aos investimentos, aparece a insistência na participação social e na integração da sociedade nacional. O populismo é essa reação, de tipo nacional, a uma modernização que é dirigida de fora. Seu tema central é rejeitar as rupturas impostas pela acumulação capitalista ou socialista, é compensar a modernização induzida através de um aumento do controle coletivo das mudanças econômicas e técnicas. Em resumo, é manter ou recriar uma identidade coletiva através de transformações econômicas que são aceitas e rejeitadas ao mesmo tempo" (TOURAINE, 1989, p. 185 , grifo no original).

Touraine faz um verdadeiro mapa dos governos e das forças que classifica como populistas na América Latina; usa como uma das variáveis dessa categoria o termo nacional-popular. Ao se defrontar como o caso chileno, nosso autor indica que "o governo democrata-cristão de Eduardo Frei, no Chile (1964-1970), é também um exemplo de governo nacional-popular" (idem, p. 205). Entretanto, Touraine nos surpreende, afrontando uma extensa gama de pesquisas sobre o tema, ao afirmar que o Brasil não conheceu um regime populista em nível nacional; aqui, teriam ocorrido apenas experiências populistas regionais, principalmente em Pernambuco, com Miguel Arraes, e no Rio Grande do Sul, com Leonel de Moura Brizola (idem, p. 198). Na nossa visão, porém, ao contrário do que expressa esse autor, identificamos que a política brasileira, por aproximadamente três décadas, esteve imersa em um sistema político profundamente identificável com o populismo. 
Francisco Corrêa Weffort seguramente é um dos pesquisadores brasileiros que mais acuradamente se dedicou ao populismo. Weffort entende tal fenômeno com a seguinte perspectiva: "O populismo foi um modo determinado e concreto de manipulação das classes populares, mas foi também um modo de expressão de suas insatisfações. Foi, ao mesmo tempo, uma forma de estruturação do poder para os grupos dominantes e a principal forma de expressão política da emergência popular no processo de desenvolvimento industrial e urbano. Foi um dos mecanismos através dos quais os grupos dominantes exerciam seu domínio mas foi também uma das maneiras através das quais esse domínio se encontrava ameaçado" (WEFFORT, 1978, p. 62-63).

Certamente, a aplicação dessa categoria teria uma eficácia explicativa muito grande para a história política brasileira, e mesmo para a de outros países latino-americanos, como a Argentina de Juan Domingo Perón e o México de Lázaro Cárdenas (PRADO, 1985). Entendemos como sendo muito pertinente sua consideração sobre as massas populares que, no populismo, encontrariam espaço para expor suas insatisfações. Entretanto, suas considerações são conhecidas por guardarem o pressuposto da existência de uma espécie de "vazio de poder"6, surgido com a crise da oligarquia na década de trinta, que permitiria o surgimento do Estado populista. Tais entendimentos deixam-nos pouco à vontade para a análise mais geral das questões relativas ao processo político latino-americano: afinal, percebemolo como sendo marcado muito mais pela incessante luta política de grupos visando à ocupação dos espaços públicos.

Dois importantes historiadores chilenos contemporâneos, Julio Pinto e Gabriel Salazar, em recente trabalho, identificaram na história política de seu país a emergência do populismo. Para eles, a decadência do desenvolvimento econômico pela qual o Chile passou, que fica expressa nas crises de 1955, 1962-1963 e 1967-1968, conformou essa

\footnotetext{
6 Para Weffort, "a participação política das classes populares tem muito a ver com as condições em que se instala o novo regime e com a incapacidade manifestada pelas classes médias e pelos setores industriais em substituir a oligarquia nas funções do Estado" (WEFFORT, 1978, p. 63). Dessa forma, "o chefe de Estado passará a atuar com árbitro dentro de uma situação de compromisso" (idem, p. 69; grifos no original).
}

maneira de condução dos assuntos políticos. Para estes autores, tal processo teve as seguintes características: "El fatídico fantasma de la 'decadencia' sólo podía ser expulsado - al parecer com una movilización nacional de las propias masas. Era necesario que los pobres vapulearam por sí mismos las 'moscas' de la decadencia. De modo que, en vez de integrarlos al 'estándar' socio-económico (o cultural) del desarrollo, era preferible integrarlos a la movilización política radical, total, contra el subdesarrollo. La responsabilidad, así, pasaba de la CPC [Classe Política Civil] y del Estado a las propias masas, pero no se les entregó, junto com eso, la 'conducción' del proceso" (PINTO \& SALAZAR, 1999, p. 163; grifos no original).

Os dois autores entendem que o governo da DC, no Chile, teve características marcadamente populistas, principalmente no que toca a sua política de Promoção Popular - a qual voltaremos a tratar adiante - que visava, como programa de governo, a incluir nos processos social, político e econômico setores marginalizados da sociedade. Porém, apesar de se nos apresentarem como importantíssimos para a análise da conjuntura de seu país, entendemos que outro autor fornece maiores possibilidades teórico-metodológicas que Pinto e Salazar para uma abordagem comparativa entre o caso chileno e o brasileiro.

Pensamos em Octavio Ianni, principalmente em seu trabalho que trata do Brasil, da Argentina e do México, qual seja, A formação do Estado populista na América Latina, como sendo o autor que mais nos fornece os elementos teórico-metodológicos necessários sobre o populismo, elementos estes que nos permitem efetivar a comparação entre as relações da DC, no Brasil e no Chile, com a aqui discutida categoria. Para esse autor, "ao analisar comparativamente movimentos, partidos e governos populistas latino-americanos, devemos adotar uma dupla perspectiva, de modo combinado. Podemos tanto focalizar o que é peculiar a este ou aquele país, em dado momento, como o que é geral, ou significativo, para vários países ao mesmo tempo. [...] Parece-nos conveniente e indispensável combinar ambas as perspectivas. $\mathrm{O}$ que é peculiar a um país, em dada ocasião, pode esclarecer-se melhor no confronto com o que parece ser freqüente em distintos países, e vice-versa" (IANNI, 1991, p. 13). Esta é, portanto, a perspectiva por nós adotada. Seguimos este caminho porque entendemos que tanto a $\mathrm{DC}$, quanto o 
populismo, em ambos os países, apresentaramse como categorias que, por vezes, conforme o seu contexto, compreendem, comparativamente, peculiaridades e generalidades, diferenças e semelhanças; dessa forma, justamente tal dualidade conformaria o ingrediente que nos permite construir uma melhor compreensão sobre ambas as categorias, quais sejam, democracia cristã e populismo.

Para Ianni, a compreensão do populismo requer que o relacionemos às crises do capitalismo mundial que colocaram em xeque, na América Latina, o modelo de exportação primária, seja ele envolvido com a agricultura, com a pecuária ou com a mineração. Tal processo acarretaria fortes tensionamentos políticos entre os diversos grupos sociais que visam a assumir o controle do Estado, que não pode mais ser conduzido apenas pela oligarquia exportadora. Todavia, nenhum dos grupos sociais tradicionais teria possibilidades de, sozinho, realizar tal tarefa, sendo necessária uma aliança com os setores sociais emergentes. Mas, ao contrário do que propõe Weffort, tal aliança "resulta muito menos do vazio político em que a sociedade se encontrava, devido à crise do poder oligárquico, do que da mudança das condições sociais, políticas e econômicas inerentes à nova situação" (idem, p. 45) 7 .

Ao apreciar como o populismo porta-se frente às diversas arenas sociais que se entrecruzam na crise estabelecida pela necessidade de uma nova relação do Estado com a economia, Ianni expressa uma formulação que utilizaremos como termo de comparação neste trabalho. Para o autor, o populismo "[...] Tende a diluir as linhas que distinguem as classes sociais e marcam os seus antagonismos, ao valorizar positivamente todas as manifestações de aliança policlassista. Em nome do nacionalismo, por um lado, e da industrialização e reforma agrária, por outro, negam-se ou mini-

\footnotetext{
7 Uma interessante análise sobre a configuração econômica da sociedade brasileira pós-1930 é feita por Eli Diniz. Expõe a autora: "A crise do café e do setor externo seria equacionada não mais em termos de uma estratégia de preservação da preponderância do setor exportador, no conjunto da economia, mas em termos da redução da vulnerabilidade de uma economia até então atrelada ao comércio exterior para a satisfação de todas as suas necessidades internas, o que levaria a um questionamento crescente do modelo agroexportador pelo menos em alguns de seus aspectos" (DINIZ, 1978, p. 64).
}

mizam-se as contradições de classe. Os movimentos, partidos e governos populistas - principalmente estes - preconizam a 'paz social', a 'harmonia das classes' ou a 'aliança entre o capital e o trabalho"” (idem, p. 160).

As formulações de Ianni são ainda mais adequadas se pensarmos na corrente discussão da história política brasileira sobre o nacional-desenvolvimentismo, mesmo porque este debate notadamente esteve presente no período da chamada democracia populista brasileira. Nesse debate, nosso autor indica, em outra importante obra, que, após 1945, quatro foram os modelos de desenvolvimento presentes na sociedade brasileira: o primeiro, e o mais antigo, é o modelo exportador, que implica a hegemonia dos setores agrícolas tradicionais, tendo como contrapartida necessária a importação de manufaturas para atender ao mercado interno; a seguir, temos o modelo de substituição de importações, visando a "encontrar uma combinação positiva e dinâmica com o setor agrário, encadeando as exigências de divisas com as exigências de investimentos destinados a atender o mercado interno" - à frente retornaremos a ele; tivemos, também, o modelo que "implica a internacionalização crescente do setor industrial, ao lado do caráter fundamentalmente internacionalista do setor agrário tradicional"; por fim, o quarto modelo desenvolvimentista seria o socialista (IANNI, 1968, p. 53-55).

Chamemos para destaque, agora, alguns apontamentos sobre o modelo de desenvolvimento marcado pela substituição de importações: "os elementos fundamentais desse padrão políticoeconômico estão consubstanciados na democracia populista desenvolvida depois de 1945" (idem, p. 54). Esse modelo, portanto, tinha em seu cerne a proposta de transferência de divisas do setor agroexportador para investimentos destinados a atender o mercado interno, reformulando drasticamente os padrões de relações do Estado com o mercado externo e, é claro, com os setores agrícolas internos envolvidos com a exportação. Visando a poder realizar essa mudança nos padrões da política econômica nacional, o Estado agiu "com base na política de massas e no dirigismo estatal, [estabelecendo] gradações nas rupturas estruturais indispensáveis a sua execução. Fundamenta a política externa independente e implica numa doutrina do Brasil como potência autônoma" (ibidem). A esse conjunto de postulados, adotados pelos atores da democracia populista brasileira, 
chamamos de nacional-desenvolvimentismo e o entendemos não como populismo propriamente dito, mas como o conjunto de políticas econômicas que os dirigentes afirmavam adotar, sem o que não poderiam sustentar a política de alianças populista ${ }^{8}$. Entretanto, um detalhe é fulcral nessa perspectiva desenvolvimentista: "caberá à burguesia industrial o comando político e ideológico do processo de desenvolvimento" (TOLEDO, 1978, p. 141).

Retornando a Ianni, outra proposição vem contribuir decisivamente para nossas reflexões. Esse autor é muito feliz ao se referir à diversidade histórica latino-americana; como ele disse, "em perspectiva ampla, o desenvolvimento desigual e combinado é inerente tanto ao conjunto da América Latina como a cada um dos seus países, considerado isoladamente. Portanto, seria ilusório tomar a América Latina como um todo homogêneo" (IANNI, 1991, p. 14). Nessas considerações, podemos confirmar nosso entendimento que entende na reflexão sobre as peculiaridades uma forma pertinente de acessar o entendimento de algo mais generalizante, no caso, a DC e o populismo.

\section{A DEMOCRACIA CRISTÃ NO BRASIL E NO CHILE E SUAS RELAÇÕES COM O POPULISMO}

Vejamos, aqui, quais inter-relações poderíamos fazer entre a DC, nas suas versões brasileira e chilena, com o populismo, e também discutir alguns pontos sobre as suas diferenças no que toca à ascensão a cargos eletivos.

\footnotetext{
8 Contribui decisivamente neste debate as considerações de Caio Navarro de Toledo. Para esse autor, o nacionaldesenvolvimentismo teve seu ápice como produção intelectual no Instituto Superior de Estudos Brasileiros (ISEB). Como marca que nos aproxima deste autor, indicamos que, segundo ele, intelectuais do ISEB como Cândido Mendes, Aberto Guerreiro Ramos, Álvaro Vieira Pinto, Hélio Jaguaribe, Roland Corbisier tinham como suposto que "na realização do desenvolvimento nacional, a aliança de classes se faria não apenas ao nível político: como afirmavam, a unidade seria alcançada também no plano ideológico. Assumia-se, assim, que no processo de desenvolvimento (industrial) - confundido com o projeto mesmo de autonomização do país periférico - a luta de classes, e por conseguinte, a luta ideológica, não se constituíam em realidade efetivas ao nível do capitalismo dependente" (TOLEDO, 1978, p. 179; grifos no original). Para nós, o nacional-desenvolvimentismo foi a proposta econômica que melhor se adaptou ao conteúdo político do populismo.
}

Na perspectiva adotada por Ianni, o período político brasileiro que começa em 1930 é entendido como inserido em um contexto populista. Entretanto, a sua configuração não foi sempre a mesma; ao contrário, sofreu modificações para que pudesse manter-se consistente. Exemplo disso foi a própria queda de Vargas, em 1945, que, mesmo abrindo as portas para o surgimento do pluripartidarismo no país, não significou o fim do regime populista. Afinal, foi a partir de então que tivemos um incremento da política de massas como maneira de organizar a vida política e legitimar o poder do Estado. Para nosso autor, "a política de massas - portanto, diferente da política de partidos - é o fundamento da democracia populista, que se organizou nas décadas que antecederão a mudança repentina ocorrida a partir do golpe de Estado de $1^{\circ}$ de abril de 1964" (IANNI, 1968, p. 9). Entretanto, não podemos passar ao largo do fato de que tal abertura política tenha permitido que se constituíssem inúmeros partidos políticos no país, entre os quais o próprio PDC.

Quanto à DC brasileira, apesar de ter se constituído como partido ainda em 1945, ela apenas conseguirá se estabelecer com alguma significância no quadro partidário nacional em 1962, quando a democracia populista estava já em profunda crise. Até esse momento, o partido foi entendido por muitos como um quadro auxiliar do maior partido de oposição daquele período, a UDN. Formaria, nas palavras de Maria Victoria Mesquita Benevides, junto com Partido Libertador (PL), Movimento Trabalhista Renovador (MTR) e o Partido Republicano (PR), uma das várias UDN (BENEVIDES, 1981, p. 224). Dessa forma, para a autora, o PDC seria uma espécie de UDN católica, o PR, a UDN do conservadorismo, o MTR, a UDN trabalhista, o PL seria claramente udenista e, "em termos de imagem pública, esses partidos eram efetivamente percebidos como ancilares ou satélites da UDN" (idem, p. 228).

Apesar disso, a DC brasileira foi, como já dissemos, no âmbito do legislativo nacional, o partido que mais vinha crescendo percentualmente entre 1954 e 1962, pulando de duas para vinte cadeiras. Lembremos também que os pedecistas brasileiros conquistaram, ainda, o governo dos estados do Paraná, com Ney Braga em 1960, e de São Paulo, com Carvalho Pinto em 1962. Nesse aspecto, é digno de nota o caráter desenvolvimentista que a administração de Ney Braga buscava adquirir: ele assumiu, no nível estadual, 
nítidos aspectos sugeridos pelo nacionaldesenvolvimentismo. Sua administração buscava "a industrialização interna via substituição de importações, tomando como referência a evasão da renda estadual provinda, ao mesmo tempo, de sua especialização agrícola (a monocultura cafeeira) e da importação de produtos manufaturados dos Estados industrializados, principalmente São Paulo" (AUGUSTO, 1978, p. I) ${ }^{9}$. Nesse sentido, observamos na proposta de Ney Braga a intenção de criar a tão sonhada autonomia nacional-desenvolvimentista no nível estadual paranaense.

Retomando a questão do crescimento da DC no Brasil, Luiz Werneck Vianna considera que "não é por acaso que em 1962 o PDC se tornará o maior partido pequeno. Radicalizadas as posições quanto à via de desenvolvimento - modernização 'por cima' versus modernização 'por baixo' - pela primeira vez amadureciam as condições para a emergência de um PDC de perfil clássico, como o italiano e o chileno" (VIANNA, 1981, p. 162). Considerando isso, é pertinente relacionar esse crescimento com um processo iniciado ainda na Presidência de Café Filho. Como bem aponta Ricardo Maranhão, a Instrução 113 da Superintendência da Moeda e do Crédito (SUMOC), baixada no início de 1955, "permitia investimentos estrangeiros diretos sem cobertura cambial, assegurando ao investidor estrangeiro a importação de equipamentos industriais segundo uma classificação prioritária dada pelo governo. Mantida esta tendência no período Kubitscheck, ela obrigaria os industriais brasileiros a se associarem a estrangeiros, abrindo a estes uma ampla gama de facilidades" (MARANHÃO, 1986, p. 264) ${ }^{10}$.

\footnotetext{
9 Nessa abordagem, também têm destaque as considerações de Ianni. Para ele, "como pólo de crescimento, São Paulo menos difunde que atrai os benefícios da industrialização. Há uma espécie de colonialismo interno que os programas nacionais e regionais não puderam limitar" (IANNI, 1968, p. 33). Visando a combater esse colonialismo interno foi que o governo da DC paranaense criou a Companhia de Desenvolvimento Econômico do Paraná (CODEPAR). A CODEPAR seria o órgão responsável para que o desenvolvimento estadual tivesse um caráter supostamente técnico e isento de demandas políticas; nesse sentido era necessária a "tecnificação de seu conteúdo, ou seja, maior 'neutralidade' face aos grupos em presença, de tal forma que sua eficácia seja maior” (AUGUSTO, 1978, p. 26).

10 Um importante estudo sobre o governo presidencial de Juscelino Kubitschek de Oliveira foi feito por Benevides. A
}

Era a economia brasileira abrindo suas portas para a associação com o capital monopolista internacional, ou seja, inserindo-se no terceiro modelo de desenvolvimento apontado por Ianni. Na medida em que este acontecimento tomava maiores proporções, mais acirradas tornavam-se as disputas no interior do pacto populista, mais desestruturado ele ficava e mais a DC ia tendo brechas para se movimentar.

Direcionemos, agora, o nosso foco para o caso chileno, onde a situação ganha um tom de maior complexidade. Afinal, não temos muitos registros de estudiosos que se debruçaram sobre a possível existência de um regime populista chileno. $\mathrm{Na}$ nossa ótica, achamos por demais ousado identificar um regime populista naquele país, mesmo porque ali existiam "partidos políticos arraigados no seio da sociedade civil e não só partidos de esquerda, mais a Democracia Cristã, fator de moderação e estabilidade no país. Os partidos políticos e as organizações de massa foram produtos da democratização crescente do país nas quase quatro décadas anteriores ao golpe" (SADER, 1984, p. 9) ${ }^{11}$. Como vimos anteriormente, aceitamos a proposição de Ianni que identifica a representação política via partidos como um componente não presente no populismo - muito ao contrário, seria mais um indício de sua inexistência.

Contudo, apesar do que afirmamos acima, sustentamos que o caso chileno pode ser problematizado de outra forma. Nesse sentido, queremos salientar que alguns pesquisadores, em oposição a, por exemplo, Vianna (1981) ${ }^{12}$, identificam no governo Frei elementos vinculados a pressupostos nitidamente populistas. Dessa

autora problematiza a estabilidade política do período, de modo que, para ela, "a estabilidade política do Governo Kubitschek foi fruto de uma conjuntura especial na qual as Forças Armadas e o Congresso atuaram de maneira convergente apoiando a política econômica cujo núcleo era o Programa de Metas” (BENEVIDES, 1976, p. 248).

11 Outra autora, Maria do Carmo Campello de Souza, entende que o sistema partidário chileno, em comparação com o do Brasil, possuía, antes do golpe militar de 1973, uma alta correlação partido-classe, bem como uma alta institucionalização (SOUZA, 1983, p. 50-51).

12 Esse autor considera que, apesar da ótica redistributivista adotada pela DC chilena, seu governo não foi necessariamente populista (VIANNA, 1981, p. 144). 
forma, recordamos que já vimos na análise feita por Pinto e Salazar a identificação de aspectos de caráter populista na DC chilena.

Para uma melhor apreciação desses problemas, retomemos um dos principais projetos da DC chilena, a Política de Promoção Popular. Esse projeto tinha o objetivo de, em seu discurso, inserir politicamente as populações suburbanas pobres e os setores camponeses que eram, em relação à democracia representativa, marginalizados. "El resultado de esta política no fue la integración efectiva de los marginales sino una marea de movilización marginal (las 'tomas de terreno' urbano quebraron las estadísticas)" (PINTO \& SALAZAR, 1999, p. 163). Essas populações foram conclamadas a participarem da vida pública, porém, sem aparelhos institucionais que lhes permitissem sentir-se inseridas nos processos de decisão. Nesse sentido, suas relações com o Estado tenderam a dar-se diretamente com o seu maior magistrado, qual seja, o Presidente da República. Nesse ponto, e referendando a hipótese de identificação de elementos tipicamente populistas no governo da DC, a Promoção Popular estava umbilicalmente ligada à proposta de um sistema comunitarista. Neste sistema, os democratas cristãos imaginavam estar evitando os extremos do capitalismo e do comunismo, pois nele "el capital y el trabajo no pertenencen ya a grupos diferentes [...] sino que se hallan unidos en las mismas manos" (GRAYSON, 1967?, p. 351). Temos aqui uma perspectiva política que é marcadamente conciliatória no que se refere ao conflito capital-trabalho, ou seja, compondo um dos elementos importantes do populismo.

Se nosso foco for direcionado para a mais propagandeada medida econômica tomada pelo governo da DC chilena, entendemos que é, inclusive, possível inseri-la na perspectiva nacional-desenvolvimentista aqui discutida. Afinal, teve grande destaque a proposta pedecista de nacionalização das minas de cobre que, por mais que não fosse um processo completo, foi um passo importante nesta direção, posto que "el convenio que propuso el gobierno a las Compañías que lo aceptaram establecía la compra del $51 \%$ de las aciones" (VITALE, 1999, p. 125). Dessa forma, podemos aproximar o caminho da DC chilena, em relação ao cobre, ao seguido pelo varguismo em relação ao petróleo.

Mais elementos que podemos considerar como populistas podem ser verificados na administração Frei. Seu enfático discurso em defesa da reforma agrária, por exemplo, esteve, na nossa ótica, bem como na de Luis Vitale, muito próximo de uma estratégia política que visava "canalizar el ascenso del movimiento campesino creando una espécie de 'colchón social' con los pequenos proprietarios favorecidos por la entrega de tierras" (idem, p. 131). Assim, em nome da reforma agrária, minimizar-se-iam os conflitos entre proprietários rurais e camponeses sem terra. Outro importante ponto a ser aqui levantado, indicando que o Presidente democrata-cristão visivelmente pretendeu ficar acima do sistema representativo estabelecendo uma ligação direta com a população -, foi sua intenção de dar ao Executivo a autoridade plebiscitária. Frei apresentou uma emenda constitucional que concedia ao presidente o direito de submeter a plebiscito popular decretos ou emendas que o Congresso Nacional recusava (GRAYSON, 1967?, p. 440). Mesmo estando o plebiscito, em tal proposta, limitado a três em cada mandato presidencial, certamente ele proporcionaria, se tivesse sido aprovado, uma grande margem de manobra para o chefe do Executivo. Desta feita, vemos em Frei a clara intenção de se sobrepor ao sistema representativo de partidos políticos, bem a moda populista.

Entretanto, nessa abordagem um cuidado precisa ser tomado. A despeito de termos verificado diversos elementos populistas na atuação administrativa da DC, concordamos com o que diz Vitale: "La administración democristiana fue 'populista', pero habría que relativizar esa afirmación o, al menos, diferenciar el populismo de Vargas, Perón y otros con el populismo freísta, una de cuyas diferencias sustanciales fue que Frei nunca tuvo un apoio mayoritario de los trabajadores organizados y menos de la CUT [Central Única dos Trabalhadores]. Por consiguiente, no pudo implementar como otros gobiernos populistas la política de estatización sindical, es decir, no pudo integrar ni controlar al movimiento sindical por medio de instituiciones del Estado" (VITALE, 1999, p. 166).

Retornemos nossa atenção ao caso brasileiro, mais uma vez. Olhando para o quadro políticopartidário de nosso país, averiguamos que, se a própria UDN, com Jânio Quadros - político que também compôs quadros junto à DC -, não pôde ficar absolutamente imune a apoiar um programa populista de governo, é certo que os democratas 
cristãos, no Brasil, não estiveram em condições de passar imunes ao regime populista. Muito ao contrário, desde a fundação esse partido teve presente em seus pressupostos aspectos profundamente ligados a este regime, como bem mostra um trecho do seu programa de 1945: "Popular, democrático e cristão - visa o PDC congregar o maior número possível de brasileiros de boa vontade - intelectuais e operários, homens e mulheres, nortistas, centristas, litorâneos e sertanejos, de todos os Estados e todas as classes, para formarem um corpo vivo e moço, cheio de confiança e de fervor, que concorra para a elevação do povo e sua participação cada vez mais ampla na vida pública nacional" (PDC, 1981 [1945], p. 470).

Mesmo a reformulação do programa pedecista brasileiro, dada em 1961, não deixou de ser generosa com apreciações populistas. Além do que já indicamos sobre este programa, gostaríamos de apontar outro princípio partidário que é intimamente carregado dos pressupostos aqui referidos: "harmonizar, no campo humano social, de um lado, os direitos e deveres recíprocos do capital e do trabalho, dentro dos postulados da justiça comutativa, distributiva e social, de forma a ligar $\mathrm{o}$ atendimento das reivindicações crescentes dos trabalhadores a novos estímulos à maior produtividade e, de outro lado, a respeitar, nas suas relações com a sociedade, com o Estado, a dignidade intrínseca da pessoa humana" (PDC, 1981 [1961], p. 472).

Pelo que apreendemos dos programas da DC brasileira, podemos visivelmente identificar proposições acerca de aliança policlassista, harmonia das classes, aliança entre capital e trabalho e, também, o nacionalismo ${ }^{13}$. Todos estes são elementos que entendemos, em concordância com Ianni, como fazendo parte dos pressupostos populistas.

Depois dessas considerações, resta-nos uma discussão sobre o fato de a DC brasileira não ter obtido o mesmo sucesso eleitoral que a chilena. Em torno desse problema, cabe destacar um importante e já referido processo que marcou a transição do Estado Novo para uma virtual democracia pluripartidária. "Virtual" porque, antes

13 O nacionalismo teve especial destaque no programa de 1961 (PDC, 1981 [1961], p. 473). de ser retirado do Executivo, Vargas conseguiu concretizar uma sólida forma de controlar algum possível processo de politização da sociedade brasileira. Lembremos o que nos disse René Armand Dreifuss sobre a questão: após o Estado Novo, foi estabelecida uma arquitetura política que limitava a participação nacional dos trabalhadores urbanos, pois a estrutura sindical era controlada pelo Estado, e a política institucional foi amarrada pelo acordo PTB-PSD (DREIFUSS, 1981, p. 27). Tendo em vista essa situação, vamos agora nos aproximar de Vianna, pois, como ele disse: "Nesse quadro, não cabia espaço para a emergência de um partido de vocação reformista, como o PDC em sua feição romana, impedido pela própria natureza da estrutura partidária de se apresentar como porta-voz das classes subalternas. Como fazê-lo, dado que, no campo, se mantinham obrigadas pelo sistema de coronelismo controlado pelo PSD e, nas cidades, ao Ministério do Trabalho e ao PTB, os quais, in casu, implementavam doutrinas sociais próprias" (VIANNA, 1981, p. 157).

Entretanto, tal aliança não poderia passar ao largo de uma dinâmica política nacional que não se apresentou imutável. Foi o que identificamos, pois, quando a aliança PSD-PTB começou a demonstrar os sinais de crise, em conjunto com o próprio regime populista, a proposta democrata cristã começou a obter melhores condições de se transformar em um alternativa política mais concreta. Tal ocorrência deveu-se, no nosso entendimento, bem como na compreensão de Maria do Carmo Campello de Souza, a um processo de realinhamento do sistema partidário que começou a apresentar seus primeiros sinais já no início dos anos cinqüenta: "verifica-se [...] que a alteração se dava em favor de pequenos partidos reformistas (PDC, PTN [Partido Trabalhista Nacional], PSB [Partido Socialista Brasileiro] e MTR), concentrados nos estados desenvolvidos, especialmente São Paulo" (SOUZA, 1983, p. 143144) $)^{14}$. Contudo, o momento de ruptura causado

\footnotetext{
14 Salientemos que algumas análises de Benevides também contribuem para uma melhor reflexão deste processo: "a associação Forças Armadas/Congresso tem seu momento de ruptura no plano da ordem, na medida em que as contradições no interior da aliança PSD-PTB e em cada partido se agravam com o radicalismo do PTB, por sua identificação com as reivindicações populares; setores do Exército passam
} 
pelo golpe de 1964 e pelo bipartidarismo brasileiro, em 1965, proporcionou uma brusca interrupção num processo que pode ser visto como de franco crescimento do PDC no país.

Ao nos dirigirmos, mais uma vez, para o sistema político-partidário chileno, ao contrário do brasileiro, vemos que ele apresentava as condições para o estabelecimento de uma democracia representativa mais substancial. Os partidos políticos do Chile, notadamente os mais à esquerda e a própria $\mathrm{DC}$, eram profundamente vinculados à sociedade civil, sendo que a própria organização partidária garantia uma boa margem de competição. Dessa forma, num período de crises econômicas e de acirramento das posições políticas, como foi a década de sessenta, o sistema político pôde abrir espaço para o discurso da DC chilena. Nas palavras do historiador Tulio Halperin Donghi, o processo deu-se, resumidamente, da seguinte forma: "Esse partido, que não queria identificarse nem com a revolução socialista nem com a defesa da ordem instituída, soube apresentar-se a uns como a única barreira contra a revolução, e a outros como o único sucedâneo ainda possível para a revolução que a ordem continental e mundial tornavam inatual" (DONGHI, 1975, p. 291). Essa hábil tática, associada a um contexto propício à aceitação de um amplo plano de reformas, abriu as portas para o estrondoso progresso eleitoral dos pedecistas chilenos.

\section{CONSIDERAÇÕES FINAIS}

Para finalizarmos, julgamos relevante retomarmos algumas formulações que fizemos, principalmente no que se refere ao marco que escolhemos para a comparação entre a DC brasileira e chilena, qual seja, a relação entre elas e o populismo. Contudo, não esqueceremos alguns pontos levantados sobre os pressupostos políticos e a ascensão aos cargos eletivos.

Tendo como referência os pressupostos políti$\cos$, averiguamos, pelo que expressaram os autores escolhidos e os programas partidários, uma profunda similitude entre os PDC dos dois paí$\operatorname{ses}^{15}$. Em ambos os casos esteve evidente a inten-

a se preocupar seriamente com o envolvimento do PTB 'janguista' com teses de 'esquerda' e com os comunistas" (BENEVIDES, 1976, p. 249).

15 Um dado que indica a aproximação entre os dois PDC, não apenas em relação aos pressupostos políticos, mas mesmo ção de se localizar em uma pretensa terceira opção, ou seja, elaboraram um programa político que propôs a construção de uma nova ordem social, a qual não estaria nem no capitalismo nem no socialismo. Entretanto, pelo que dissemos sobre a atuação dos democratas cristãos em relação às demandas dos setores populares, como no caso da Previdência Social, para o Brasil, e da repressão a mobilizações, para o Chile, a atuação destas DC acabou, no máximo, tendo um papel de organizar politicamente as forças da modernização reformista. Acabou, no nosso modo de ver, contestando muito mais radicalmente o socialismo revolucionário do que propriamente o capitalismo vigente em seus países.

Ao nos dedicarmos às relações entre $a D C$ e o populismo, bem como à diferente visibilidade eleitoral que ambos os PDC lograram nas quadras históricas brasileira e chilena, entendemos ser necessária uma apreciação mais acurada. Neste ponto, foi fundamental as contribuições formuladas por Ianni. Com ele, pudemos perceber a possibilidade metodológica de realizar satisfatoriamente a comparação entre os dois contextos históricos aqui focalizados. Vimos, com este autor, que as generalizações feitas sobre a categoria populismo para a América Latina puderam nos auxiliar na compreensão das especificidades de cada problemática histórica nacional. Nesse sentido, tivemos a oportunidade de averiguar as peculiaridades das DC brasileira e chilena em relação à categoria populismo. Com efeito, pudemos, ainda, notar que a configuração das propostas democratas cristãs em cada país, ou seja, um dado de caráter específico em nossas reflexões, possibilitou-nos uma compreensão mais detida sobre algo mais geral, o próprio populismo. Desta forma, bem à moda de Ianni, as especificidades nos permitiram um melhor entendimento de um conjunto mais generalizado. Sendo assim, mesmo que não tenhamos encontrado situações idênticas nos dois países, isso não nos impediu de fazer uso do marco histórico comparativo como um instrumento para, com mais acerto, apreendermos as diversidades históricas aqui focadas. Muito ao contrário, foi a não similitude que, na nossa perspectiva, permitiu uma comparação e um entendimento mais acurado.

sobre uma atuação política mais ordenada, foi a participação de ambos da ODCA. 
Portanto, seria indispensável, para discutirmos alguns pontos que ajudem no entendimento dos processos que diferenciaram a conformação da DC no Brasil e no Chile, refletirmos se o populismo teria ou não, e ainda, de que maneira, se configurado em ambos os países. Também importa, neste momento, algumas considerações sobre o sentido em que as DC se inserem em tal processo.

Dessa forma, o Brasil comportou um evidente regime populista por volta das três décadas que antecederam o golpe de Estado de 1964. Este regime teve como uma de suas marcas a crescente necessidade de inserir, de alguma maneira, um contingente urbano cada vez mais numeroso, e às vezes rural, no processo político do país. As singularidades locais levaram à configuração de um regime populista que, num dado momento, imprescindiu de um sistema pluripartidário. Nesse sistema foi nitidamente materializado o pacto populista, a partir de 1945, pela aliança PSD-PTB; essa aliança sustentou-se de tal forma que impediu não só o efetivo crescimento da DC, como de qualquer outro agrupamento partidário.

Portanto, o sistema político-partidário impediu estruturalmente uma ascensão eleitoral mais saliente dos pedecistas brasileiros. Apenas quando o sistema partidário iniciou uma tendência ao realinhamento e a aliança PSD-PTB começou a estremecer, que o PDC teve a chance de alçar um crescimento eleitoral mais perceptível. A partir desse momento, a DC começou, em um processo lento, a desvincular-se de sua situação de simples satélite ou ancilar da UDN - relativizamos, assim, as proposições de Benevides. Todavia, devemos salientar que os pedecistas brasileiros não puderam, como de resto nenhum dos partidos do período pôde, em absoluto, escapar a uma imposição estrutural do próprio regime populista, qual seja, adotar, em dado momento, alguns pressupostos e atitudes políticas de caráter populista. Sem isso não obteriam qualquer possibilidade de sobrevivência político-eleitoral. Contudo, a condição de se perfilar ao lado do nacional-desenvolvimentismo, tão propalado no período, não pode figurar de modo concreto nas posições de todos os partidos, visto que aqueles que se enfileiravam junto ao internacionalismo-associativista, como a UDN, não puderam assumir tal perspectiva de modo programático. Quando o fizeram, foi em questões nas quais tal perspectiva adquiria, por força das alianças populistas em determinados contextos, como a nacionalização petrolífera, tamanha relevância que proporcionava a imposição de um consenso nacional. Ainda nessa questão, não podemos deixar de lado que o PDC no governo paranaense chegou, mesmo, a adotar um quase estadual-desenvolvimentismo.

No caso chileno, tivemos uma conformação política diferente da brasileira. Para o período que nos dedicamos, o Chile, em oposição ao Brasil, possuiu uma democracia representativa acompanhada de um sistema partidário fortemente institucionalizado. Não identificamos, entre os chilenos, portanto, a consecução de um regime populista, mas sim a existência de elementos populistas no agrupamento partidário que nós focalizamos. A conformação desses elementos tem a possibilidade de ser melhor analisada se, na nossa ótica, a relacionarmos com um contexto histórico no qual se configuraram três componentes essenciais: sucessivas crises econômicas; um momento de acirramento das posições políticas; e a necessidade de convencer diversos setores urbanos e alguns rurais da possibilidade de integração nos sistemas sócio-econômico e político vigente.

Considerando isso, na década de sessenta, o sistema político chileno abriu espaço para a consecução de uma alternativa reformista: foi aí que a DC chilena se fortaleceu. Entretanto, as sucessivas crises econômicas acabaram empurrando o governo Frei para uma política marcada por aspectos populistas, visando a acomodar os setores sociais que o apoiavam, mas que demandavam da administração reivindicações antagônicas entre si. Foi mister, como expuseram Pinto e Salazar, tendo em vista que a decadência econômica não permitiu uma efetiva integração sócio-econômica dos setores marginalizados, ao menos estabelecer uma mobilização social de tais setores, pois suas posições políticas estavam cada vez mais radicalizadas. Esse processo passou a impelir a administração Frei à adoção de posturas e atitudes de cunho nitidamente populistas. O próprio tema central de sua campanha eleitoral, e depois título do seu programa de governo, Revolução em liberdade, parece-nos muito sugestivo nessa perspectiva. Também nos auxilia nessa aproximação a nacionalização das minas cupríferas, impulsionada pelo governo democratacristão, e em sintonia com o desenvolvimento industrial nacionalista. Mas é de fundamental importância, neste momento, que tenhamos em evidência as cuidadosas apreciações de Vitale: nem 
mesmo a administração da DC realizou, no Chile, por exemplo, o controle do Estado sobre o movimento sindical.

Recebido para publicação em 15 de agosto de 2000.

Sandro Anselmo Coelho (sandrocoelho@yahoo.com.br) é Mestrando em História na Universidade Federal do Paraná (UFPR).

\section{REFERÊNCIAS BIBLIOGRÁFICAS}

AUGUSTO, M. H. O. 1978. Intervencionismo estatal e ideologia desenvolvimentista : estudo sobre a CODEPAR (Companhia de Desenvolvimento Econômico do Paraná). São Paulo : Símbolo.

BENEVIDES, M. V. M. 1976. O governo Kubitschek : desenvolvimento econômico e estabilidade política (1956-1961). Rio de Janeiro : Paz e Terra.

1981. A UDN e o udenismo: ambigüidades do liberalismo brasileiro (1945-1965). Rio de Janeiro : Paz e Terra.

CHACON, V. 1981. História dos partidos brasileiros : discurso e práxis dos seus programas. Brasília : Edunb.

DINIZ, E. 1978. Empresário, Estado e capitalismo no Brasil : 1930-1945. Rio de Janeiro : Paz e Terra.

DONGHI, T. H. 1975. História da América Latina. Rio de Janeiro : Paz e Terra.

DREIFUSS, R. A. 1981. 1964 : a conquista do Estado. Ação política, poder e golpe de classe. Petrópolis : Vozes.

GRAYSON JR., G. 1967? El Partido Democrata Cristiano chileno. Santiago : s/n.

IANNI, O. 1968. O colapso do populismo no Brasil. Rio de Janeiro : Civilização Brasileira.

. 1991. A formação do Estado populista na América Latina. Rio de Janeiro : Civilização Brasileira.

INCISA, L. 1999. Populismo. In : BOBBIO, N.; MATTEUCCI, N. \& PASQUINO, G. (orgs.) Dicionário de política. Brasília : Edunb.

MARANHÃO, R. 1986. Estado e política 'populista’ no Brasil (1954-1964). In : FAUSTO, B. (org.). História geral da civilização brasileira. Tomo III : O Brasil republicano (1930-1964), vol. 9. São Paulo : DIFEL.
1988. O governo Kubitscheck. São Paulo : Brasiliense.

MAYEUR, J.-M. 1999. Partidos católicos e democrático-cristãos europeus. In : BOBBIO, N.; MATTEUCCI, N. \& PASQUINO, G. (orgs.) Dicionário de politica. Brasília : Edunb.

PARTIDO DEMOCRATA CRISTÃO (PDC). 1981 [1945]. Programa partidário. In : CHACON, V. História dos partidos brasileiros : discurso e práxis dos seus programas. Brasília : Edunb.

1981 [1961]. Programa partidário. In : CHACON, V. História dos partidos brasileiros : discurso e práxis dos seus programas. Brasília : Edunb.

PARTIDO DEMOCRATA CRISTIANO (PDC). 1968. Estadisticas electorales : elecciones generales y complementarias de 1963 a 1968. Santiago : Departamento Electoral Nacional.

PINTO, J. \& SALAZAR, G. 1999. Historia contemporánea de Chile, v. I : Estado, legitimidad, ciudadanía. Santiago : LOM.

PRADO, M. L. 1985. O populismo na América Latina. São Paulo : Brasiliense.

SADER, E. 1984. Democracia e ditadura no Chile. São Paulo : Brasiliense.

SOUZA, M. C. C. 1983. Estado e partidos políticos no Brasil (1930-1964). São Paulo : Alfa-Omega.

TOLEDO, C. N. 1978. ISEB : fábrica de ideologias. São Paulo : Ática.

TOURAINE, A. 1989. Palavra e sangue: política e sociedade na América Latina. São Paulo/ Campinas : Trajetória Cultural / Edunicamp.

VIANNA, L. W. 1981. O sistema partidário e o Partido Democrata Cristão. In : FLEISCHER, D. V. (org.). Os partidos políticos no Brasil. Brasília : Edunb. 
VITALE, L. 1999. El primer gobierno DC :

Eduardo Frei Montalva. In : __ et alli.

Para recuperar la memória histórica: Frei,
Allende y Pinochet. Santiago : ChileAmérica.

WEFFORT, F. C. 1978. O populismo na política brasileira. Rio de Janeiro : Paz e Terra. 